\title{
Optimum volumetric computation of fluvial sediment deposits in reservoirs by comparative analysis of different hydrographic survey methodologies
}

\author{
Demetris Zarris ${ }^{1}$, Evdoxia Lykoudi ${ }^{2}$ \\ ${ }^{1}$ Department of Water Resources and Environmental Engineering, School of Civil Engineering, National \\ Technical University of Athens, 5, Heroon Polutechneiou St., Athens, 15780 Greece ${ }^{1}$ \\ ${ }^{2}$ Department of Geological Sciences, School of Mining Engineering and Metallurgy, National Technical \\ University of Athens, 5, Heroon Polytechneiou St., Athens, 15780, Greece.
}

\begin{abstract}
Reservoir sedimentation studies provide a useful tool for the determination of the actual sedimentation rate and the computation of the real useful life of the reservoir. This task is often carried out with a full hydrographic survey of the reservoir, which feeds data to a Digital Terrain Model (DTM) of the reservoir's invert. In other regions of the world, this task is alternatively accomplished with the range lines surveying technique, which is less accurate but is less expensive and copious and therefore suitable for developing countries and large scale reservoir systems. This paper examines these two different approaches of the volumetric computation of the sediment deposits at Kremasta reservoir, Western Greece. The volume of the deposited sediment for the Agrafiotis segment of the reservoir was calculated from the DTM survey and was accepted as the true sediment volume. The accuracy of the range line technique was tested against the DTM survey using five different sets of range lines. The results show a considerable underestimation of the sediment volume for all the sets of range lines. The underestimation is more evident when the range lines are sparse and it is shown that beyond a certain number of range lines there is no improvement of the overall estimation.
\end{abstract}

Key Words: reservoir sedimentation, hydrographic survey, Digital Terrain Model, range line, Stage-Width modification method, Kremasta reservoir.

\section{Introduction}

\subsection{The necessity for reservoir hydrographic surveys}

The deposition of sediment in reservoirs can variously impact their performance through storage capacity losses, damage to valves and conduits, reduced flood attenuation and changes in water quality. Due to flow deceleration when a river approaches a reservoir, the sediment transport capacity decreases, and some, if not all, of the incoming sediment is trapped and deposited in the reservoirs. In addition, the deposited sediments may consolidate by their weight and the weight of overlying water through time. World-wide reservoirs are loosing their storage capacity at an annual rate of about $1 \%$, approximately corresponding to $50 \mathrm{~km}^{3}$ loss every year [1]. The determination of the reservoir sedimentation rate is a very difficult task at the design phase of the reservoir and it's not rare the cases where the underestimation of the real sediment incoming load was impressive. Because of these underestimations, reports of reservoirs silting up at ten times their design rates are not uncommon. For instance, the useful life of the Sefidrud reservoir in Iran was predicted in the design stage to exceed 100 years. However, after some years, measurements indicated a much higher rate of sediment deposition and updated prediction reduces the useful life to only 30 years. The Louros reservoir is a characteristic example for the Hellenic region where the reservoir was completely filled of sediments after some years of the reservoir operation and its hydroelectric station operates only taking advantage the instantaneous discharge of the river. Reservoir surveys are often required for, among other reasons [1,2,3], (a) to establish or update stage - volume curves for reservoir operation surveys, (b) to calculate the sediment yield of the upstream hydrological basin, (c) to assist reservoir designers to the design of other reservoirs in the region, (d) to predict the spatial distribution of sediment within the reservoir and in particular close to hydraulic structures such as intakes, and (e) to evaluate methods of prevention or sediment removal. The significance of sedimentation data may be considerable. For instance, if the reservoir operates a hydroelectric power station or supplies an irrigation scheme, then its projected life expectancy is of vital economic importance both for assessing the financial returns and for estimating the cost of corrective maintenance. In this situation it is essential for the reservoir managers, in areas of high sediment yield values, to have the ability to assess the effect of sedimentation on their reservoirs. Reservoir surveys are the most reliable technique available for assessing the

${ }^{1}$ Corresponding author: D. Zarris, Tel:+30-210-7722091

E-mail: zarris@ hydro.ntua.gr 
accuracy of the design life, the current storage characteristics and the necessity for erosion control measures in the catchment. This necessity is much more vital in the cases for small reservoirs which facilitate hydroelectric projects. The objective of this paper is to make a comparative analysis of the two most widely used methods of reservoir surveying, the DTM surveying and the range lines surveying and to assess the possibility of installing a network of range lines in order to accomplish frequent surveys with the least expenditure and maximum approximation of the volume of deposited sediments.

\subsection{Digital Terrain models}

The most accurate method, currently available, of surveying a reservoir is to use a survey vessel linked to an automatic positioning system and a depth measurement instrument, which feeds data into a Digital Terrain Model (DTM). This operation is often called a hydrographic (or bathymetric) survey of a reservoir. This method requires a huge quantity of both positioning and bathymetric data. A typical DTM survey may require that data points are never more than $50 \mathrm{~m}$ apart. Survey lines, both parallel and perpendicular to the original river course, are thus defined by a $50 \mathrm{~m}$ grid over the entire reservoir surface and from them a digital computer can accurately re-create the reservoir's three-dimensional pattern. Provided the computational power of modern computers and the plethora of relative software packages; this is not really a problem. The real constraining problem with DTM surveys is the expense of carrying out such operation. In order to take the appropriate number of data points, certain instrumentation and manpower are required. A modern and very accurate Global Positioning System (GPS) is prerequisite for precise determination of positioning of the hydrographic vessel and a bathymetric instrument from a simple echo-sounder to a very complex sub-bottom profiler is required for the precise measurement of the reservoir depth. In addition, someone may add the expense of the specialized staff for carrying out the measurements but also for the post-processing of the collected data.

\subsection{Range line surveys}

In many places, particular in developing countries, reservoir managers continue to use range line surveying techniques. A range line is essentially a cross section of the reservoir, perpendicular to the main course of the original river. Consider the hydrographic survey based on depth measurements in a given number of range lines. The area of deposition, $\mathrm{S}$, in a range line, $\mathrm{y}$, is estimated by the simple trapezoidal rule as:

$$
S(y)=\sum_{i=1}^{n} \frac{H\left(x_{i}, y\right)-H\left(x_{i-1}, y\right)}{2}\left(x_{i}-x_{i-1}\right)
$$

where, $x i$ is the horizontal coordinate of a survey point, $i=1, . ., n ; H$ is the observed depth of sediments and $n$ is the number of survey points. The trapezoidal rule can be used for calculating, using point measurements, the areas in a range and the volume between ranges. The total volume, Vol, is estimated by using (1) with crosssectional areas $\mathrm{S}(\mathrm{y})$ and the distances y between ranges

$$
\mathrm{Vol}=\sum_{k=1}^{N} \frac{S\left(y_{k}\right)+S\left(y_{k-1}\right)}{2}\left(y_{k}-y_{k-1}\right)
$$

where $\mathrm{N}$ is the number of ranges.

If the weight of the deposition is to be estimated, the average bulk density should also be known. This quantity can be estimated by sediment sampling [4,5] or using a regression method based on inflow sediment size distribution [6]. It is difficult to make a precise recommendation as to the number of range lines that should be used for a post impoundment survey as the sensitivity of the method to range line spacing varies with the type and complexity of the reservoir involved. The number of range lines is assumed to be a crucial parameter in determining the accuracy that might be achieved from a hydrographic survey and is related more to reservoir shape than reservoir size. A first indication of the number of range lines that may be required is given by the USBR [7] from the equation

$$
N=14.3 A^{0.29}
$$

where, $\mathrm{N}$ is the required number of range lines and $\mathrm{A}$ is the reservoir surface in $\mathrm{km}^{2}$. This equation makes no allowance for additional range lines needed to cope with a complex reservoir pattern.

\subsection{Kremasta reservoir}

\section{Materials and Methods}

The Kremasta reservoir was constructed in 1964 and is located in North-Western Greece. The reservoir area at the spillway crest is $80.6 \mathrm{~km}^{2}$ and the total storage volume is $4495 \mathrm{hm}^{3}$. The reservoir watershed has an area of $3292 \mathrm{~km}^{2}$, elevation ranging from $+284 \mathrm{~m}$ to $+2433 \mathrm{~m}$ and the mean annual inflow to the reservoir equals $117.1 \mathrm{~m}^{3} / \mathrm{s}$. This inflow is largely provided by Acheloos River and to a lesser extent by Agrafiotis River and Megdovas River (Fig. 1). Mean annual precipitation equals $1433 \mathrm{~mm}$. The geology of the catchment is 
largely dominated by limestone and flysch. The latter shows a considerable erosion potential which is mainly responsible for the high sediment yield of the whole basin.

The reservoir was surveyed during the years 1998 and 1999. We particularly draw attention to the Agrafiotis segment of the reservoir for our comparative analysis. This particular segment, which is actually the river delta as it enters the reservoir, exhibits the least complex pattern of all the streams that entering the reservoir, with a considerable sedimentation rate. In fact, the mean annual sediment yield of the Agrafiotis upstream basin was estimated equal to $2035 \mathrm{t} / \mathrm{km}^{2}$, which is one of the highest values reported in the international literature [3]. Therefore, it was selected for our analysis so as to succeed in the least distortion of the results from the complexity of the terrain.

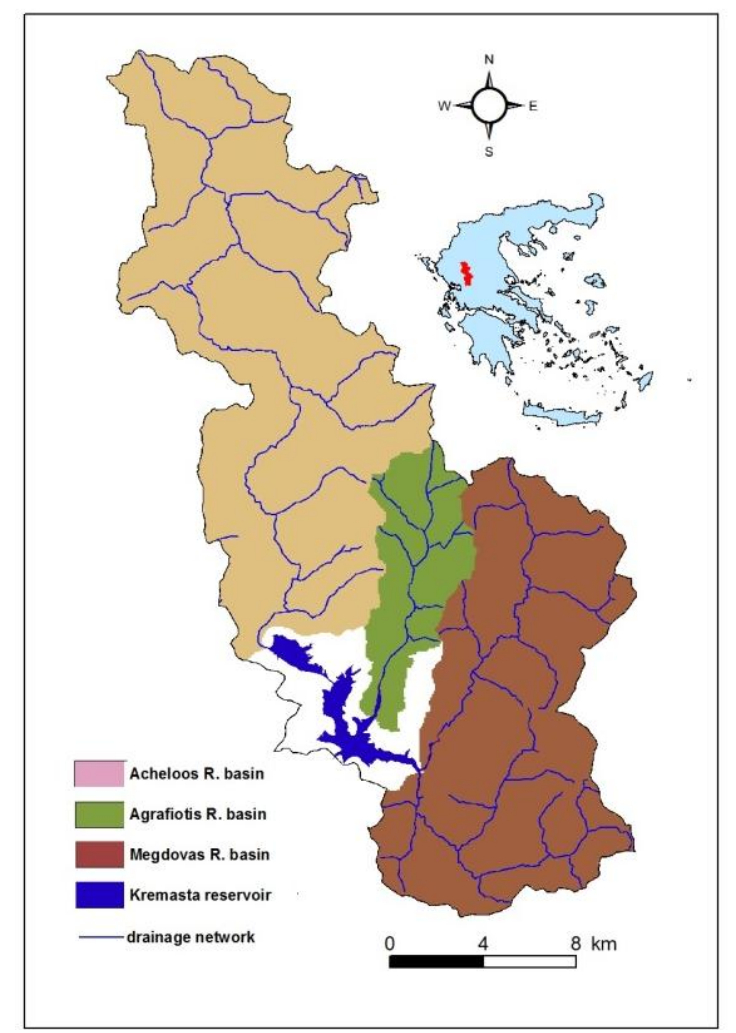

Fig. 1: Kremasta reservoir and its hydrological basin.

\subsection{Description of DTM hydrographic survey}

A key element of the proposed method is to construct the DTMs for two periods of interest, one prior to the dam construction (1964) and the other during the hydrographic survey (1998-99). The hydrographic survey has been carried out using a differential Global Positioning System (GPS) technique and a typical fathometer (echo-sounder) operating at the frequency of $130 \mathrm{kHz}$ for depth determination. Therefore the method is subject to the usual errors e.g. GPS limited availability and the definition of the water-mud interface. The average distance of the hydrographic routes of the vessel was between $50 \mathrm{~m}$, where most of the sediment deposits was expected, (e.g. river deltas) and $200 \mathrm{~m}$ in the central part of the reservoir. The DTM at the time prior to the dam completion was constructed from digitizing the original survey maps (scale 1:5000). The corresponding DTMs from both the hydrographic survey and the initial topographic maps resulted from an irregular network of points in three dimensions (position and elevation), which constitute the base for the construction of the Triangulated Irregular Network (TIN). The associated grids were interpolated from the TINs by utilizing triangulation with linear interpolation procedures available in the SURFER mapping package. Both models are constructed with a $6 \mathrm{~m}$ by $6 \mathrm{~m}$ grid. The difference in elevation results in the volume of deposited sediments. The spatial distribution of accumulated sediment in the reservoir shows profoundly that the total incoming sediment remains in the reservoir and particularly at the uppermost parts (deltaic deposits) (Fig. 2). The volume of the deposits at the Agrafiotis section of the reservoir is computed equal to $13.1 \mathrm{hm}^{3}$ [3]. The area of the reservoir segment occupied by sediment deposits is equal to $2.5 \mathrm{~km}^{2}$ while the length of the segment is almost $5.5 \mathrm{~km}$. The depth of the deposits ranges from $5 \mathrm{~m}$ to $10 \mathrm{~m}$. 


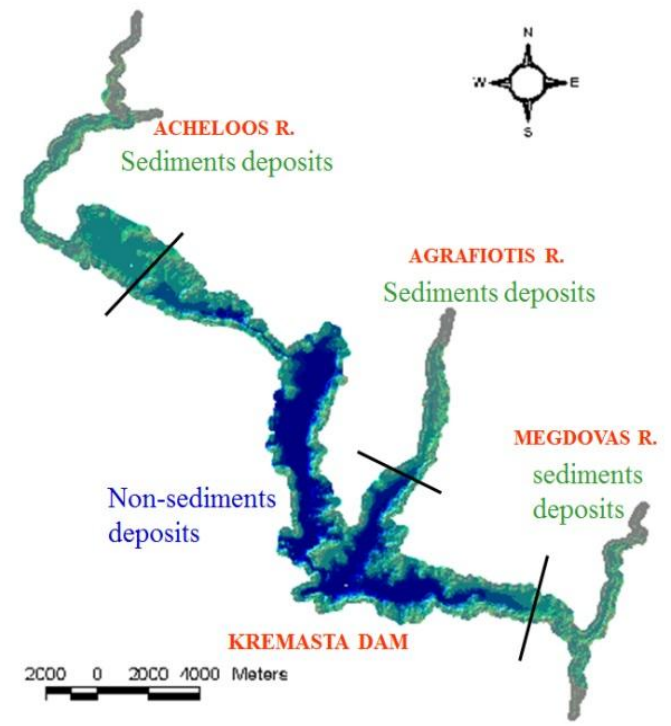

Fig. 2: Spatial distribution of deposited sediment at Kremasta reservoir.

\subsection{Description of range - line sediment volumetric computation}

The analysis described hereafter refers to the same reservoir area. According to the first indication by USBR the required number of range lines should be equal to 19. In this paper, five sets of range lines consist with 7, 16, 19, 27 and 33 range lines respectively. The main objective is to determine how the increase of the number of range lines affects the sediment volume estimation and how far this estimation is from the "real" value derived from the DTM procedure. Hypothetical range lines are derived from the DTM survey using simple procedures in the SURFER mapping package. For instance, in Figure 3, two hypothetical range lines from the Agrafiotis section of the reservoir are presented showing the depth of sediment deposits.
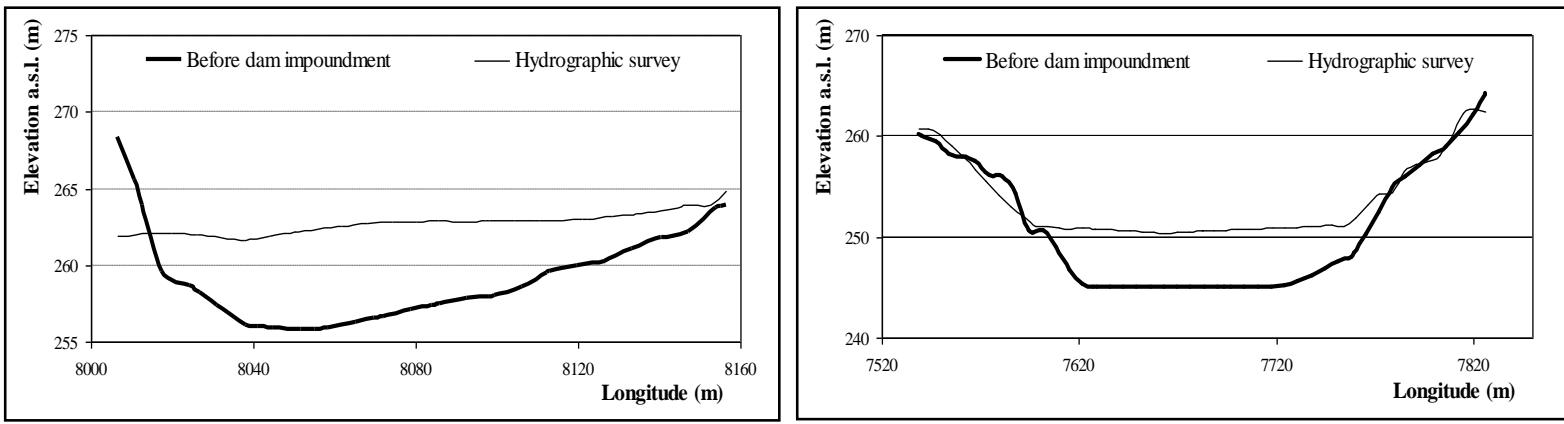

Fig. 3: An example of two hypothetical range lines of Agrafiotis segment for sediment volume estimation.

The volume of the deposited sediment is calculated using the RESSASS model [7]. It uses an algorithm, which is a slight modification of the trapezoidal rule, and it is called the Stage-Width Modification Method [2]. A stage-width is a graph of depth on the $\mathrm{y}$-axis against section width on the $\mathrm{x}$-axis. The volume of a segment is computed by fitting a stage-area curve, which describes the relationship between depth and the plan area of the segment at that depth. An assumption is made, that is at a given depth, the width changes linearly between the upstream and downstream widths. Volume is calculated by integrating the stage-area curve for a reservoir reach. Figure 4 presents the hypothetical network of range lines for almost all the available sets of range lines.

Range lines selected are not generally equidistant, but their selection is based on the change of certain reservoir characteristics (e.g. width) and they are also restricted in the same reservoir segment extent. The results are presented in Table 1. It is evident that there is a significant underestimation of the total sediment volume with respect to the "true" volume resulted from the DTM survey. The volume of sediment deposits results as the difference between the total volume of stored water before the reservoir impoundment at a given level and the volume of stored water at the hydrographic survey for the same level. This specific level is actually the absolute elevation of the reservoir stage during the hydrographic survey, which is assumed constant $(+269 \mathrm{~m}$ a.s.l.). 

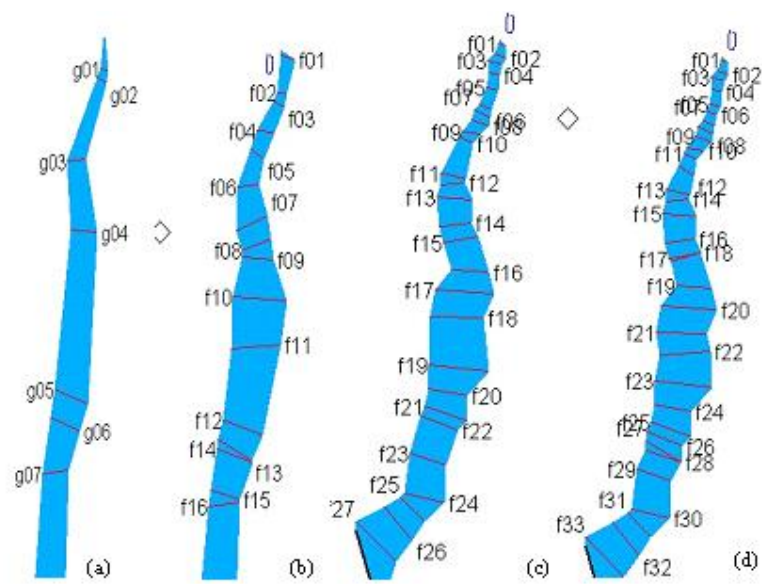

Fig. 4: Hypothetical range lines for four sets of deposition simulation (a) 7 range lines, (b) 16 range lines, (c) 27 range lines, and (d) 33 range lines.

Table 1: Results of the analyses for five sets of range lines

\begin{tabular}{|c|c|c|c|c|c|}
\hline $\begin{array}{c}\text { No of } \\
\text { range lines }\end{array}$ & $\begin{array}{c}\text { Sediment } \\
\text { volume } \\
\text { estimation } \\
\left(\mathrm{hm}^{3}\right)\end{array}$ & $\begin{array}{c}\text { Reservoir } \\
\text { volume }\left(\mathrm{hm}^{3}\right) 1\end{array}$ & $\begin{array}{c}\text { Reservoir } \\
\text { volume }\left(\mathrm{hm}^{3}\right) 2\end{array}$ & $\begin{array}{c}\text { Percentage sedimentation } \\
\text { of original reservoir } \\
\text { volume }\end{array}$ & $\begin{array}{c}\text { \% Difference with } \\
\text { sediment volume from } \\
\text { DTM survey }\end{array}$ \\
\hline 7 & 8.89 & 83.09 & 74.20 & 10.70 & 32.1 \\
\hline 16 & 9.72 & 91.83 & 82.11 & 10.59 & 25.8 \\
\hline 19 & 9.81 & 93.21 & 83.40 & 10.53 & 25.1 \\
\hline 27 & 10.78 & 100.58 & 89.80 & 10.72 & 17.7 \\
\hline 33 & 10.53 & 101.34 & 90.81 & 10.53 & 19.6 \\
\hline
\end{tabular}

\section{Results and Discussion}

Sediment volume estimation using the range lines surveying methodology results in our case in a considerable underestimation of the real sediment volume. Even at the best case, that is the one with the 27 range lines, the percentage difference with the real volume is almost $18 \%$, or in absolute terms, $2.4 \mathrm{hm} 3$ of sediments. With less number of range lines it's even worse, the underestimation is above $30 \%$ with a set of 7 range lines $(4.21 \mathrm{hm} 3)$ and above $25 \%$ with a set of 16 range lines $(3.38 \mathrm{hm} 3)$. Volume analysis becomes more accurate when the number of range lines is increasing until further increase of the range lines seems not to improve the volume calculation. It is not clear whether it is a systematic underestimation valid for all possible reservoirs since the volumetric computation is mainly dependent on the reservoir configuration and also on the subjective and arbitrary range lines selection. However, for this specific case, it seems that the underestimation is serious and may affect possible remedial plans for reservoir maintenance and sediment extraction. Even at the best case, the average distance between ranges equals to $200 \mathrm{~m}$, which tends to be as time-consuming and copious as the DTM surveying technique. Accordingly, for the value of range lines indicated by the USBR the underestimation is almost $25 \%$ of the real value. It is concluded that the DTM surveying technique remains a superior methodology for the accurate calculation of reservoir deposits. Range lines technique should be used with caution for developing countries where the financial resources are extremely limited or when very frequent surveying is required (e.g. small reservoirs for hydroelectric plants) and also when the additional costs for sediment extraction is counterbalanced from the reduced expenditure of the range line surveying technique. It is proposed that before installing a network of range lines for frequent and continuous monitoring of reservoir sedimentation rates, a full DTM hydrographic survey should be carried out first. This has to be done in order to establish a range line network with the maximum possible approximation of the real sediment volume.

\section{Acknowledgments}

This work is a continuation of the research project "Appraisal of river sediment deposits in reservoirs of hydropower dams" funded from the General Secretariat of Research and Technology (GSRT) and the Public Power Corporation (PPC). We would like to thank Mr. T. Zissopoulos and our colleagues in the Department of Topography of the National Technical University of Athens for their valuable assistance during the hydrographic survey of the reservoir. We are also indebted in the Hydraulic Research Ltd at Wallingford,

1 Volume of stored water at a given reservoir stage before the reservoir impoundment.

2 Volume of stored water at a given reservoir stage at the hydrographic survey 
England, for the very kind offering of the RESSASS software. The authors would like also to thank Demetris Koutsoyiannis, research coordinator of the project, for his valuable comments and assistance during the research project.

\section{References}

[1] Sloff, C.G., Reservoir sedimentation: A literature survey, Communications on hydraulic and geotechnical engineering, Delft University of Technology, 1991, 126.

[2] Lea, N.J. 1991. Analysis of reservoir range lines surveys using the stage width modification method, Report OD/TN 56, April, HR Wallingford, 1991,18.

[3] Zarris, D., Lykoudi, E. and Koutsoyannis, D., Sediment yield estimation from a hydrographic survey: A case study for the Kremasta reservoir basin, Greece, Proceedings of the 5th International Conference "Water Resources Management in the Era of Transition", Athens, 4-8 September, 2002, 338-345.

[4] Lane. E.W. and Koelzer, V.A., Density of sediments deposited in reservoirs, Rep. No. 9, St. Paul US Engrg., District Sub-Office Univ. of Iowa, USA, 1943.

[5] Borland, W. M., Reservoir sedimentation.. In: River Mechanics, edited by H.W. Shen, Water Resources Publications, Fort Collins, Colorado, 1971, 29.1-29.38

[6] Miller, R.C., Determination of the units weight of sediment for use in sediment volume computations, Technical Report, USDA, Washington DC, 1953, 5.

[7] Hydraulic research LTD, Measuring and predicting reservoir volume changed due to sedimentation: RESSASS Version 1.5, User Manual, Wallingford, England, 2001. 